Aprovado em: 24/03/2019

\title{
MEMÓRIA NO COTIDIANO DA HIPERINFORMAÇÃO: SOBRE TODA A MEMÓRIA DO MUNDO
}

\section{MEMORY ON THE EVERYDAY OH HYPERINFORMATION: ABOUT ALL OF THE MEMORY IN THE WORLD}

\author{
Nicholas ANDUEZA ${ }^{1}$, Carlos Affonso MELLO
}

\section{Resumo}

Traçamos uma reflexão sobre as relações entre memória e esquecimento no cotidiano hipermidiático da modernidade tardia. Nesse percurso, observamos a desvalorização histórica do esquecimento, passeamos por trechos do curta Toda a memória do mundo (1956), de Alain Resnais, e abordamos o chamado Big data, o grande excesso de informações que se espalham pela rede. Vivemos em um contexto de alta rotatividade, produção e armazenamento de conteúdos múltiplos, viabilizado por tecnologias de computação e pela internet. Frente a pedagogias da memória que permeiam essa cultura e a projetos reais de armazenamento total do Big data, qual seria a função e o lugar do esquecimento?

Palavras-chave: cibercultura; cotidiano; memória; esquecimento; arquivo.

\begin{abstract}
We would like to reflect on the relationship between memory and oblivion in the everyday hypermedia flow of late modernity. In this way, we can observe the historic devaluation of forgetting and we achieve this by examining some excerpts from the short film All of the memory in the world (1956), by Alain Resnais. We also tackle the so-called Big data, or the overwhelming excess of information that spreads through the web. We live in a context of high circulation, production and storage of multiple forms of content, which are enabled by computation technologies and by the Internet. In a context in which memory practices permeate such culture and in which one can find real projects for total storage of the Big data, one important question emerges: what would be the function and the place of forgetting?

Keywords: Cyberculture; Everyday; Memory; Forgetting; Archive.

\footnotetext{
${ }^{1}$ Doutorando em Comunicação e Cultura na UFRJ com bolsa CNPq. Professor de cinema em cursos de curta duração em Nova Friburgo - RJ. Editor de cinema e audiovisual. E-mail: nicholasandueza@gmail.com.

${ }^{2}$ Doutorando em Comunicação Social na PUC-Rio. Pós-graduado em Filosofia Contemporânea (2011) pela mesma instituição. E-mail: loscar.affonso@gmail.com.
} 


\section{Introdução}

Neste artigo $^{3}$ traçamos uma reflexão sobre as relações entre memória e esquecimento em uma sociedade marcada pelo uso da internet e por dispositivos produtores e disseminadores de conteúdo e interatividade (celulares, laptops, câmeras, desktops, games etc.). Nesse percurso, tratamos do chamado Big data, o grande leviatã formado por informações de todos nós, que estão espalhadas e interconectadas por essa entidade que chamamos Rede, ao mesmo tempo em que analisamos trechos de um curtametragem de Alain Resnais, intitulado Toda a memória do mundo (1956) ${ }^{4}$.

Optamos por essa abordagem por considerarmos que o curta aborda pontos estruturais da forma como produzimos e lidamos com o atual excesso de arquivos, particularmente no que diz respeito à maneira de operarmos mecanismos de memória e de esquecimento. E pensar tais mecanismos nos direciona ao cerne da comunicação humana propriamente dita, que se baseia na transmissibilidade de informações, culturas, signos, conceitos, contextos. A função de memória inscrita nessa transmissão, como vamos demonstrar, já é historicamente reconhecida; mas nos perguntamos sobre o lugar de uma função de esquecimento. Gostaríamos de propor um olhar para o esquecimento como gesto sistemático para a construção de narrativas (históricas ou pessoais) e para a vivência do presente (já que a memória se atrela ao passado), e não como simples falta, ausência de narrativa, que é como costumamos pensá-lo (HUYSSEN, 2014).

Para tanto, propomos um olhar sobre pedagogias da memória no cotidiano hipermidiatizado da modernidade tardia: registrar, compartilhar, salvar. São gestos corriqueiros que, por isso mesmo, por serem feitos a todo o momento e de modo banal, nos comunicam características estruturais do nosso tempo.

\section{Diferentes meios e comunicações}

Após os créditos iniciais de Toda a memória do mundo, vemo-nos dentro de uma sala escura e sem delimitações evidentes - plano inicial do filme. Diante de nós, surge

\footnotetext{
${ }^{3}$ Este é o desenvolvimento de um artigo apresentado em 2017, no Póscom, evento regional de PósGraduação em Comunicação na PUC-Rio (AUTOR, 2017).

${ }^{4} \mathrm{O}$ curta está disponível em: <https://www.youtube.com/watch?v=H13LtP5eltI>.
} 
um instrumento criado pelo homem, uma tecnologia da visão, uma câmera. Uma câmera, numa sala escura. O enquadramento se move e redescobrimos, pela mudança de perspectiva, os contornos dessa máquina diante de nós. Mas por pouco tempo, porque nos afastamos dela. Entra em cena, tão próximo de nós quanto já esteve aquela câmera, um microfone. A voz off nos fala: "porque nossa memória é curta, os homens acumulam inumeráveis dispositivos". E neste ponto, saímos do microfone e vamos a uma montanha de livros, revistas e jornais. Tudo dentro da mesma sala, escura; tudo dentro do mesmo plano-sequência.

Ao fim desse caminho, vemos, entre os objetos de leitura, um refletor desligado. Ele ganha nossa atenção à medida em que é centralizado no enquadramento. O refletor, de repente, liga-se sozinho e o brilho serve de transição ao plano seguinte, como numa sinapse que produz e conecta o fluxo do pensamento: estamos em uma espécie de cérebro das coisas, um cérebro-artefato. $\mathrm{O}$ ambiente exibido pelo primeiro plano do filme, por não apresentar delimitações visíveis e se desdobrar em dispositivos de memória que se materializam aos poucos, insinua-se como lugar onde o limite das paredes é desconhecido e parece sempre se expandir para fazer caber. Há aí qualquer coisa de onírico e misterioso. Lugar de memória, espaço de aparência ilimitada. E nesse breve passeio feito durante o plano de abertura do curta, nos deparamos com um fato relevante: da câmera aos jornais, os dispositivos encarregados da extensão da memória humana são também dispositivos de comunicação.

A história humana e a história da comunicação se confundem. Ainda que sem o interesse em fazer História propriamente ${ }^{5}$, desde tempos imemoriais nossos ancestrais buscavam entender o mundo ao seu redor e a si mesmos por meio de sua predileção pela comunicação, ou, para sermos mais abrangentes, pela linguagem. Por meio desta, talvez o mais antigo dos nossos dispositivos (AGAMBEN, 2009, p.41), o ser humano é capaz de comungar presença e ausência, subjetividade e mundo, destilando do concreto um

\footnotetext{
5 Não é de interesse deste trabalho analisar se havia ou não preocupação historiográfica de nossos antepassados. Escrevemos do nosso hoje, deste momento da história, e para tanto nos valemos das palavras de Moses Finley que diz que "o passado só pode oferecer corroborações paradigmáticas para as conclusões que tiramos do presente; o passado, em outras palavras, ainda pode ser tratado da mesma forma atemporal com que tratamos os mitos" (FINLEY, 1989, p. 25).
} 
abstrato dizível, fazível, pensável, armazenável: transmissível. Assim, no coração da linguagem, junto com uma destilação de essências, está o gesto de comunicabilidade delas (BENJAMIN, 2012, p.121 e 122), de usar o arcabouço do comum (signos compartilhados por outros) justamente para tornar comum (comunicar a outros). E pela repetição e continuação desse gesto, substratos se acumulam, sobrepõem-se, implicam-se mutuamente de modo a formar uma colcha de retalhos que, de uma perspectiva generalizante, conhecemos como "cultura". Ocorrem por incontáveis meios os modos de produção, reprodução e apreensão dessas construções de saber e de ser, dessas técnicas que se estendem de um passado remoto até nossos dias.

Olhando em retrospectiva, é possível identificar uma história dos meios, que conta sobre si mesma e sobre a história do mundo que conhecemos. Os aedos de outrora, ou as figuras que em determinada comunidade antiga estavam destinadas a transmitir o legado de seus antepassados, eram os meios de comunicação de seu tempo, as interfaces entre passado, presente e futuro - eram corpos transtemporais, nódulos centrais da cultura e da linguagem. Mas temos que ter cuidado ao entender que eles representavam "o máximo poder da tecnologia de comunicação" (TORRANO, 2007, p. 16) nas sociedades de tradição oral; cuidado para não homogeneizarmos os diversos processos históricos das comunicações humanas.

Há pelo menos duas formas comuns de praticar essa homogeneização. Primeiro, assumindo que as culturas orais pertencem a um "outrora", a um "antanho" indeterminado. Segundo, entendendo que as tecnologias da tinta rupestre, da escrita, do papiro, da prensa, da máquina de escrever, do computador, da internet, dos laptops e dos celulares seriam passos progressivos de uma mesma linha de busca pela comunicação total que as sociedades expressariam desde sempre.

Nos dois casos, não só negaríamos a existência atual e continuada de culturas não absorvidas pela modernidade (de modo bem abrangente: culturas de fora da zona urbana e/ou desligadas de seu sistema de organização e de trocas), como também deixaríamos de olhar para possíveis traços de resistência a esse tempo homogeneizante do capitalismo na própria cultura urbana. Isso seria contribuir para o processo de apagamento das culturas não acometidas de modernidade, o que pode tomar proporções bem violentas, como, por 
exemplo, nos embates entre índios e latifundiários no interior do Brasil. E seria também produzir uma sensação, que na prática não é verificável, de universalidade do projeto moderno, invisibilizando diferenças históricas por meio de uma abordagem tecnicista e teleológica, que não vê senão um avanço progressivo da tecnologia.

De modo geral, a comunicação está, sim, atrelada à tecnologia, a arcabouços técnicos que viabilizam transações simbólicas e conceituais entre as pessoas, num sentido amplo em que até mesmo uma língua pode ser concebida como tecnologia. É isso que nos exibe o primeiro plano do curta de Resnais: a necessidade humana de produzir dispositivos para lembrar. Contudo, esse elo comunicação-tecnologia não precisa ser interpretado de modo tecnicista e teleológico, o que seria uma perspectiva moderna homogeneizante. Há formas diversas de comunicar, e é tendo isso em mente que Walter Benjamin traça diferenças fundamentais entre o narrador (ou contador) e o romancista: enquanto o primeiro vem da tradição oral de sociedades artesanais e holistas, o segundo se insere fortemente na tradição escrita das sociedades industriais e individualistas (modernas), nas quais a comunicação não tem por base o mito e a experiência vivida, mas sim o romance psicológico/ explicativo e a informação jornalística (BENJAMIN, 2012, p.219).

De todo modo, como é corroborado pela leitura benjaminiana, o contexto midiático e tecnológico é em grande medida determinante para a produção de formas discursivas e comunicacionais. Ou seja, o cotidiano ao mesmo tempo forma e é formado pelo modo como realizamos nossas trocas comunicativas. Nessa esteira, é sabido que a invenção da prensa de tipo móvel, em meados do século XV, por Johannes Gutenberg, na Alemanha, entre outras coisas, possibilitou a Reforma e promoveu uma revolução científica (LOGAN, 2012; THOMPSON, 2013). E que, sem a prensa, uma cultura do romance dificilmente teria tomado as proporções que tomou. Sociólogos e teóricos da mídia como John B. Thompson (2013) chegam a alertar para a dificuldade de se compreender as sociedades modernas sem entender a importância do papel social da mídia em sua formação. O desenvolvimento de novos meios e tecnologias ao longo dos séculos seguintes à prensa, tais como a fotografia, o cinema, o rádio e a televisão, além de afetar profundamente a relação sujeito-mundo, inaugurando novos paradigmas do 
conhecimento e novas práticas discursivas, também lançou novas abordagens para o armazenamento informacional.

Em todas as sociedades os seres humanos se ocupam da produção e do intercâmbio de informação e de conteúdo simbólico. Desde as mais antigas formas de comunicação gestual e de uso da linguagem até os mais recentes desenvolvimentos na tecnologia computacional, a produção, o armazenamento e a circulação de informação e conteúdo simbólico têm sido aspectos centrais da vida social [...] a partir do século XV até os nossos dias, os processos de produção, armazenamento e circulação têm passado por significativas transformações. (THOMPSON, 2013, p.35. Grifos nossos).

\section{Tecnologia, cultura hipermidiática e excessos de memória}

Ao longo de Toda a memória do mundo somos apresentados a um sistema ao mesmo tempo amplo e hermético de armazenamento das produções humanas: a Biblioteca de Paris. O curta gira em torno dela, apresentando e descrevendo seus vários processos. Longe de uma noção romantizada da biblioteca como uma espécie de templo do saber, Resnais nos apresenta uma biblioteca fabril, absolutamente inserida nos ritmos modernos de produção não só de mercadorias como de informação e, por conseguinte, de arquivos. Sob essa perspectiva, os processos de guarda que assistimos aparecem como linhas de produção, processos semiautomáticos, quase "maquínicos", em que persiste uma utopia de memória totalizante.

Esses processos revelam uma face particularmente dramática quando somos informados pela voz off que um único departamento da Biblioteca de Paris, o de periódicos, recebe diariamente $200 \mathrm{~kg}$ de papel sob a forma de vários exemplares de jornais e revistas, que devem ser preservados para consultas posteriores (lembrando que esses dados são da década de 1950!). Somos apresentados, então, aos homens que levam os papéis até os interiores da Biblioteca, a câmera deixa os mensageiros e acompanha os sacos cheios de periódicos enquanto eles descem por um elevador de carga.

Um outro funcionário recebe a carga e a despeja na mesa. Em seguida, vemos alguns planos de homens e mulheres manuseando cada jornal e revista para catalogar as novas entradas e preservá-las, separando, nomeando, carimbando, transportando, guardando. E em todo esse processo, acompanhamos os arquivos seguindo em uma linha 
de montagem para seu armazenamento, passando insensivelmente pelos corpos humanos que, nesse percurso, têm funções bem delimitadas e repetitivas (alienadas?). Assim, vemos de perto como a inserção da biblioteca em um cotidiano marcado pela modernidade produz uma adequação dos mecanismos de memória a um sistema industrial capitalista: a alta circulação e produtividade também no armazenamento.

Com as tecnologias do computador e da internet, a capacidade de produção, armazenamento e circulação de informação foi catapultada a um nível que parece extrapolar muitas vezes a nossa compreensão. Em pouco mais de meio século os recursos técnicos oriundos das pesquisas nessa área foram crescendo em progressões impressionantes, a ponto de hoje podermos afirmar com alguma segurança que, se não a totalidade do conhecimento até hoje disponível, uma parte considerável já se encontra estocada no que parece ser uma ampla memória de base digital.

Contudo, ela não representa apenas a soma de tudo que se produz e reproduz nos ambientes digitais (o big data). Ao menos em certa medida, pode ser vista como a reificação de conceitos caros aos estudos de memória: uma personificação da vontade de memória e das práticas de memória de que falam Nora (1993) e Namer (1987); uma versão atualizada da memória coletiva de Halbwachs (2015); um signo de uma obsessão da cultura contemporânea como coloca Huyssen (2014); uma perspectiva aos trabalhos de enquadramentos de memória de Pollak (1989).

Quando pensada in totum, tal "memória” dá a impressão de ser algo mundialmente integrado - e o é, na medida em que entendemos a Internet como uma rede, isto é, como uma estrutura que proporciona interconexão entre suas partes. Quando vista de modo aproximado, essa grande memória é percebida como composta por fragmentos - e o é, na medida em que há certa independência entre cada um de seus nós: o acervo digitalizado de uma biblioteca na Argentina guarda autonomia em relação ao arcabouço de dados de uma universidade no Brasil, que por sua vez funciona de maneira independente em relação aos arquivos de nossos computadores pessoais.

Independentemente de estar alojada somente em um determinado ponto dessa estrutura (um disco rígido específico de acesso, em tese, restrito ou um servidor que atua internacionalmente enviando e recebendo dados de terceiros), podemos entender que uma 
dada informação habita uma estrutura comum junto a outras informações. Como sugerido acima, é possível sustentar que essa estrutura funcione como uma espécie de memória coletiva, promovendo a interseção entre correntes de pensamento (HALBWACHS, 2015) e uma prática específica de acumulação que dá origem a múltiplos itinerários da memória (NAMER, 1987). Como explica Pierre Nora:

Nenhuma época foi tão voluntariamente produtora de arquivos como a nossa, não somente pelo volume que a sociedade moderna espontaneamente produz, não somente pelos meios técnicos de reprodução e de conservação de que dispõe, mas pela superstição e pelo respeito ao vestígio. A medida em que desaparece a memória tradicional, nós nos sentimos obrigados a acumular religiosamente vestígios, testemunhos, documentos, imagens, discursos, sinais visíveis do que foi, como se esse dossiê cada vez mais prolífero devesse se tornar prova em não se sabe que tribunal da história (NORA, 1987, p.15).

O que autor descreve é uma pedagogia da memória que está atrelada à hiperprodutividade cotidiana de arquivos por cada um de nós. Acessível em nível individual, produzindo, armazenando e fazendo circular informações (lembranças, memórias) de naturezas diversas (fotos de aniversários, textos acadêmicos, dados ultrassecretos, senhas de cartões de créditos, fórmulas químicas, manuais de construção de armas em impressoras 3D), essa grande memória englobante (NAMER, 1987) segue engolindo não apenas nossas pegadas digitais, mas também aspectos da realidade dos ambientes off-line. Devora, estoca e agencia uma saturação informacional sem precedentes. Daí talvez a constatação de que a memória não existe mais (NORA, 1987). Na verdade, parece estar ausente por uma hiperpresença, uma onipresença que induz a pensar que talvez haja memória até demais. Onde tudo é memória, não faz mais sentido falar em lugar de memória.

Diante disso, é ilustrativo que o volume de informação gerada mundialmente tenha dobrado somente nos três primeiros anos do século XXI, possivelmente surpreendendo até mesmo as previsões mais otimistas dos entusiastas das tecnologias digitais. Mais recentemente, em outubro de 2015, o site da revista Forbes publicou alguns números a respeito desse gigantesco repertório de conteúdos que as tecnologias do computador tornaram possível. Segundo a publicação, o volume de dados criado em 2014 
e 2015 foi maior do que a quantidade produzida em toda a história da humanidade. As cifras são astronômicas. Termos como megabyte, gigabyte, e mesmo terabyte, tão comuns no cotidiano de algumas sociedades contemporâneas, parecem irrelevantes - hoje os dados armazenados são da ordem dos chamados zettabytes (ou $\mathrm{ZiB})^{6}$.

Ainda segundo o site, até 2020 ao menos 1/3 de todas as informações divulgadas no mundo passarão pela rede de servidores conectados à internet, indicando uma concentração cada vez maior de dados em locais muito bem definidos, isto é, em espaços físicos com imensa capacidade de armazenamento. Vale ressaltar que tal cenário não é fruto do acaso. Não é à toa que a Agência de Projetos de Pesquisa Avançada (ARPA), responsável pelo empreendimento que levou à criação da internet (tal qual a conhecemos), era vinculada ao Departamento de Defesa dos EUA (BLUM, 2013; CASTELLS, 1999/2010).

Corroboram a tese de um grande projeto de armazenamento em escala global os muitos depoimentos apresentados no documentário Freenet (2016), mas especialmente o do jornalista americano Glen Greenwald. Em certa passagem, o vencedor do Pulitzer 2014 é explícito ao mencionar o papel da Agência de Segurança Nacional americana (NSA) e da Sede de Comunicações Governamentais britânica (GCHQ) na coleta e estocagem das informações que circulam pela rede. "Eles querem coletar tudo. Eles não querem coletar alguma informação, eles não querem coletar muita informação. Eles querem coletar a Internet como um todo para armazená-la”, afirma Greenwald ${ }^{7}$.

Para sermos ainda mais específicos, convém mencionar o ambicioso projeto da NSA, já em vias de conclusão, conhecido como Utah Data Center. O imenso complexo, que está sendo construído na cidade de Buffdale (Utah, EUA), pretende guardar o registro da totalidade do que trafega na rede, com a colaboração de gigantes do mercado, como Google, Facebook e Yahoo!. De acordo com o escritor americano Nicholas Carr, em menos de vinte anos, a internet se tornou o meio de comunicação e busca de informação de preferência universal. Nesse contexto, o autor observa que: "o alcance do seu uso é

\footnotetext{
${ }^{6}$ Estima-se que a quantidade de dados armazenados hoje seja de aproximadamente 4,4 $\mathrm{ZiB}$, e que esse número passe os $44 \mathrm{ZiB}$ (ou 44 trilhões de gigabytes) em até cinco anos. A título de curiosidade, vale mencionar que $1 \mathrm{ZiB}$ corresponde a 1 byte acompanhado por 21 zeros do lado direito.

${ }^{7}$ A passagem mencionada se localiza em $01 \mathrm{~h} 15$ '00" do filme.
} 


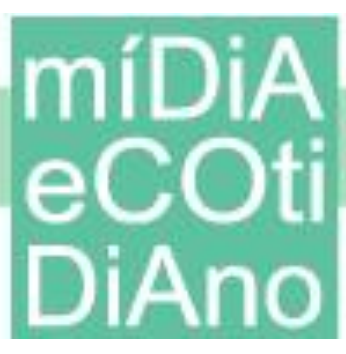

sem precedentes [...] o alcance de sua influência é igualmente amplo. Quer por escolha, quer por necessidade, adotamos o modo praticamente instantâneo da net de coletar e distribuir informação" (2011, p. 23).

Em teoria, nada de novo. Afinal, como já apontaram as obras de Foucault e Deleuze, as instituições privilegiadas com o exercício de diversas formas de poder (econômico, político, coercitivo, simbólico etc.) se beneficiam do regime contínuo de vigilância, das práticas discursivas e de seus registros históricos como forma de punir dissidentes e controlar espaços, corpos e mentes. Mas, além das implicações políticas e econômicas, uma memória tão potente, virtualmente capaz de armazenar o todo, desde informações sobre as pinturas rupestres da caverna de Lascaux até conversas entre amigos trocadas por e-mail, parece desafiar a razão.

\section{O lugar do esquecimento}

Desse ponto de vista, quais implicações esse tipo de empreendimento pode ter para o cotidiano, a sociabilidade e as relações humanas de modo geral? Em outras palavras, como pensar uma memória que não esquece? No limite, como pensar a possibilidade de pensar sem esquecer? Não estaríamos diante de fenômenos complementares? Não seria o esquecimento também a condição de possibilidade de uma memória equilibrada? (NIETZSCHE, 1887/2008; HEIDEGGER, 1926/2007; RICOEUR, 2000/2014; HUYSSEN, 2014).

Obviamente não estamos a falar de um esquecimento que decorre de doenças como Alzheimer ou de lesões físicas que comprometem as funções cerebrais, como no caso de acidentes. O esquecimento do qual tratamos é o mesmo de que fala Pierre Lévy, ao argumentar que "a operação da memória não pode ser concebida sem as aparições e supressões que a desagregam, que a moldam de seu interior" (LÉVY, 2011, p. 133). Essas supressões e aparições são as inconsistências, os momentos em que a memória é banhada pelas incertezas de Léthê, ${ }^{8}$ possibilitando que o inesperado aja e que em certa medida uma "humanidade" apareça.

\footnotetext{
${ }^{8}$ Esquecimento, um dos cinco rios do Hades junto com Aqueronte, Cócito, Estige e Flegetonte.
} 
Na cultura contemporânea, obcecada como é pela memória e o trauma, o esquecimento é sistematicamente malvisto. É descrito como uma falha da memória: clinicamente, como disfunção; socialmente, como distorção; academicamente, como uma forma de pecado original; em termos de vivência, como um subproduto lamentável do envelhecimento. Essa visão negativa do esquecimento, é claro, não é surpreendente nem particularmente nova (HUYSSEN, 2014, p.155).

O esquecimento possui um papel importante na cultura do Ocidente, integrando muitas vezes diretamente a pedagogia de tempos passados. Para exemplificar isso, lembremo-nos da Teogonia, obra clássica do "poeta-cantor" Hesíodo, que data aproximadamente dos séculos VII/VIII a.C. Nesse poema mitológico, em que nos é apresentada a genealogia dos deuses gregos, alguns personagens têm uma importância central: o próprio aedo, enquanto meio de acesso à história a ser contada; Zeus, enquanto fonte de todo poder; a deusa Mnemosyne (Memória), enquanto energia que garante a circulação das forças entre os domínios do Visível e do Invisível; por fim, as Musas (Mousaon), filhas de Zeus e Memória, que são as forças de desocultação, isto é, de presentificação do mundo.

"Como desocultação é que os gregos antigos tiveram a experiência fundamental da Verdade”, explica o filósofo José Torrano (2007, p. 25), sendo alétheia a palavra grega para Verdade, que em seu significado mais profundo quer dizer "não ocultado", 9 não esquecimento. Segundo Torrano (2007, p. 26), “o próprio ser das Musas geradas e nascidas da Memória as constitui como força de esquecimento e de memória, com o poder da presença e [da] ausência". É enquanto filhas da deusa que as nove musas permitem trazer à luz os fatos que estavam esquecidos ou os relegar ao Esquecimento (léthe, lesmosyne) - uma alegoria que já antecipa o clássico embate filosófico entre o ser e o não ser.

Podemos perceber a relevância do esquecimento nas origens do pensamento ocidental também na obra de Platão. Em uma conhecida passagem de Fedro, o filósofo conta ao seu interlocutor que, não por coincidência, dá nome ao texto, sobre um mito de origem da escrita. Explica que ao inventar o cálculo, a geometria, a astronomia, o jogo de

\footnotetext{
${ }^{9} \mathrm{O}$ alfa privativo $a$ expressa uma negação; o verbo lanthano significa "estar oculto".
} 
gamão e a tecnologia da escrita, o deus Toth se apresentou ao rei Tamuz, "mostrou-lhe suas artes e disse-lhe que deviam ser distribuídas entre os demais egípcios" (PLATÃO, 2016, p. 136). Recebeu críticas e elogios para cada uma de suas invenções, mas, quando chegou o momento de falar da escrita, a divindade fez questão de frisar que se tratava de uma novidade que faria o povo mais sábio e que melhoraria sua memória.

O episódio se desenrola com o governante questionando Toth sobre sua obra e apontando para o que provavelmente seria um tiro pela culatra, pois os homens deixariam de exercitar a memória ao restringirem o conhecimento aos registros escritos. Por conseguinte, estariam mais propensos a cair em esquecimento. Mas as raízes dessa aversão em relação ao esquecimento já provocavam reviravoltas e enriqueciam a cultura grega há mais tempo. Afinal, teria existido uma Ilíada se Aquiles, de pés ligeiros, não tivesse optado por morrer e entrar para a história como o campeão da Grécia em vez de viver sua vida modicamente e ser esquecido? ${ }^{10}$

Os exemplos encontrados na Alegoria da Caverna e no Mito de Er, ${ }^{11}$ apresentados respectivamente nos Livros VII e X d'A República, ajudam-nos a compreender a importância do esquecimento na Paideia grega. A teoria idealista de Platão, que nos apresenta a hierarquia da busca pelo conhecimento, pressupõe haver uma etapa anterior - e ao final, posterior - à materialidade do mundo, em que a alma, antes de retornar à Terra, faria uma travessia pela Planície e pelo Rio do Esquecimento. Chegando a este mundo em um corpo com uma memória fragmentada, a alma necessitaria se reconhecer, relembrar-se para se tornar completa novamente em um caminho em direção ao "mundo inteligível".

Ainda assim, percebemos que o esquecimento possui até aqui uma conotação negativa, sendo sempre um estado do qual se quer (e se deve) manter distância. Como explica Andreas Huyssen (2014, p.155), "quando se trata de teorizá-lo, o esquecimento

\footnotetext{
${ }^{10}$ Vale recordar que mais tarde, na Odisseia, Aquiles se lamentará a Odisseu por estar morto: “(...) não venhas, solerte Odisseu, consolar-me da Morte, pois preferiria viver empregado em trabalhos no campo sob um senhor sem recursos, ou mesmo de parcos haveres, a dominar deste modo nos mortos aqui consumidos" (HOMERO, 2015, p. 198).

11 O Mito de Er nos apresenta a Teoria da Reminiscência (da Transmigração da Alma ou apenas Metempsicose), de origem órfico-pitagórica, e que influenciou profundamente o platonismo, o neoplatonismo e mesmo doutrinas mais recentes como o espiritismo.
} 
aparece, na melhor das hipóteses, como um complemento inevitável da memória, uma deficiência, uma falta a ser suprida, e não um fenômeno de múltiplas camadas". É no começo da Segunda Dissertação da Genealogia da Moral, de Nietzsche, que encontraremos pela primeira vez uma problematização sobre o esquecimento, uma teorização em defesa do tema. Sobre isso, diz-nos o filósofo alemão:

Esquecer não é uma simples vis inertiae [força inercial], como creem os superficiais, mas uma força inibidora ativa, positiva no mais rigoroso sentido, graças à qual o que é por nós experimentado, vivenciado, em nós acolhido, não penetra mais em nossa consciência [...] Fechar temporariamente as portas e janelas da consciência; permanecer imperturbado pelo barulho e a luta do nosso submundo de órgãos serviçais a cooperar e divergir; um pouco de sossego, um pouco de tabula rasa da consciência, para que novamente haja lugar para o novo [...] eis a utilidade do esquecimento, ativo, como disse, espécie de guardião da porta, zelador da ordem psíquica, da paz, da etiqueta: com o que logo se vê que não poderia haver felicidade, jovialidade, esperança, orgulho, presente, sem o esquecimento (NIETZSCHE, 2008, p.47).

A radicalidade da reflexão nietzschiana reside não tanto em sua proposta de pensar o esquecimento como algo ativo, uma "contra-faculdade". Diferentemente do exercício de rememoração, não se esquece porque se quer esquecer, simplesmente é algo que acontece. $\mathrm{O}$ interessante do raciocínio apresentado é que ele confere à dimensão do esquecimento uma função positiva, não a enxergando apenas como uma ausência pura e simples, indo fundo na ideia de que só há memória porque há esquecimento. Mais adiante, o autor chega a comparar aquele que não esquece a um ser dispéptico, ou seja, a um ser que não consegue digerir seu alimento, que está fadado a permanecer refém do desconforto proporcionado pela má digestão.

Para Nietzsche, não há presente sem o esquecimento, exatamente porque, diante de uma memória absoluta, só há passado. E vem daí a reflexão do filósofo acerca do ressentimento, pois aquele que não se permite esquecer estaria condenado a re-sentir, a sentir sempre novamente. Por não digerir o alimento da consciência, não realizar a “assimilação psíquica" (NIETZSCHE, 1887/2008) daquilo que experimenta, o homem se privaria de viver o presente e, no limite, até mesmo de se debruçar sobre seu futuro. 


\section{míDiA

\section{Memória "monstruosa"}

Logo depois da sequência de abertura de Toda a memória do mundo (descrita acima), Resnais passa a nos mostrar a monumentalidade da Biblioteca de Paris. Os movimentos laterais e circulares da câmera, que segue o em torno das colunas, das grades, dos degraus, produzem um efeito de paralaxe que enriquece a visão e aumenta o espaço. Toda essa construção de planos móveis parece dizer não só que a biblioteca é imensa, mas também que ela é muito maior que cada indivíduo que a frequenta ou que trabalha em suas linhas de produção.

Aqui é válido reiterar a relação que o historiador Jacques LeGoff trabalha entre as noções de monumento e documento (1990). Se o documento tende a ser lido como prova, como evidência, o monumento por sua vez é uma obra claramente interessada em fazer valer um discurso. Le Goff dá o exemplo dos arcos do triunfo, costume romano antigo para celebrar vitórias militares construindo arcos comemorativos, como monumentos de memória. Contudo, é preciso notar que, por se tratar de um produto humano, não há documento neutro, e isso significa que todo documento deve ser olhado na verdadel como monumento. Invertendo os polos, também é possível dizer que todo monumento, de certa forma, documenta um ponto de vista do poder. A magnitude da biblioteca de Resnais nos dá essa pista de um projeto moderno utópico. Mas essa "monumentalidade", feita para a guarda de "documentos", não precisa de tamanho para acontecer, como é o caso dos dispositivos mais recentes de comunicação, capilarizados para o uso individual e, portanto, pequenos.

Nessa perspectiva, um exemplo bastante ilustrativo provém do terceiro episódio da primeira temporada do seriado televisivo Black Mirror (Inglaterra, 2011/...) produzido pela Netflix. Esse capítulo conta a história de um casal que vive em uma sociedade em um futuro não muito distante em que as pessoas têm acesso a um implante ótico que grava tudo o que se vê e ouve - um modelo mais avançado que o protótipo recém-patenteado da Samsung. O dispositivo não apenas grava, mas permite que o implantado acesse todos os dados armazenados (vividos), tal qual uma memória. Só que diferentemente de uma memória, digamos, analógica, que suprime momentos, que constrói narrativas, a memória 


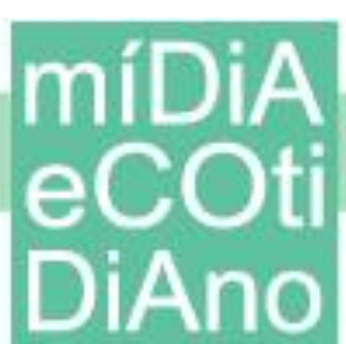

digital do aparelho é fidedigna ao passado: o que se viveu é gravado e o que é gravado é o que foi vivenciado. Há pouca margem para interpretações.

Aparentemente partilhando de um relacionamento leve e sólido, o casal começa a ter problemas quando, por ocasião de um encontro entre amigos, o marido percebe uma conversa suspeita entre sua esposa e um conhecido. Como basta olhar para gravar, o rapaz resolve acessar a cena mais tarde em casa. Mais que isso: utiliza recursos tecnológicos de leitura labial e aumento de volume ambiente para verificar o conteúdo do que havia sido conversado. Descobre que ambos falavam de um momento anterior ao evento em questão, o que coloca em xeque a versão de sua esposa de que havia sido a primeira vez que estivera com essa pessoa.

A partir de então a história de ambos se torna o que o imaginário popular poderia considerar um inferno, pois sendo movido por ciúme e insegurança (e pela pedagogia inerente da tecnologia de seu dispositivo ótico) o marido entra em um modo insano de vida. Passa a verificar todos os seus arquivos em busca da construção de uma narrativa baseada em dados que sustentem a "versão oficial" de que sua esposa o traía. Assim permanece por dias, confrontando sua companheira sempre que possível - incapaz de esquecer e de superar o passado. Uma crise conjugal se abate sobre o casal, que por fim se separa.

O episódio em questão traz outros momentos interessantes que merecem reflexão, mas o exemplo acima nos parece suficiente para corroborar o argumento de que o acesso a uma memória total, na qual não haja espaço para o "sossego", corresponde a um despropósito e mesmo a um perigo: uma memória assim "consideramo-la até mesmo monstruosa" (RICOEUR, 2014, p. 424). Se considerarmos a etimologia, entendemos uma outra camada na afirmação de Ricouer, dado que a palavra monstro compartilha do mesmo radical que monumento (monere): há uma monumentalidade na memória monstruosa, e uma monstruosidade na memória monumental. Outros episódios da série - 


\section{míDiA

e também de outras séries ${ }^{12}$ - igualmente recorrem à "harmonia oculta" dessas "forças opostas": ${ }^{13}$ a memória e o esquecimento para organizar suas tramas.

Assim, o cenário inaugurado pelas tecnologias do computador, especialmente neste início de século XXI, de alguma forma ratifica e atualiza a ideia de que "a lembrança está ali, fora de nós, talvez dispersa entre muitos ambientes" (HALBWACHS, 2015, p. 59), especialmente os digitais. A sociedade em rede, ao mesmo tempo em que pulverizada em uma multiplicidade de individualidades, é mais facilmente capturada - e vale lembrar que capturar é a função primordial de uma rede - e estratificada em determinados segmentos. A vida cotidiana deste novo século parece gerar um paradoxo no qual uma quantidade virtualmente infinita de memória também acarreta uma espécie de terceirização desta: não lembro um número de telefone ou uma informação qualquer porque sei que ambas estão ali, acessíveis.

A memória, social ou psíquica, é antes de tudo uma experiência da perda. Ela é certamente uma presença do passado que se revive em parte pela lembrança, mas é também uma consciência da ausência, do tempo que não volta, do tempo que altera (ROUSSO, 2016: 32).

A experiência da perda implicada na memória nos fala da constância do esquecimento, sentinela das mudanças do tempo. Mas essa perda tal como se dá hoje, pela via da terceirização da lembrança em dispositivos de tela e teclado, pode aproveitar o par memória-esquecimento para fins do poder. Isso porque há uma oposição brutal entre o imenso arquivo que acumula a totalidade da memória versus o indivíduo comum, que recorre ao GPS do celular para acertar o caminho na estrada (tanto na ida como na volta). Ao concentrar toda a memória do mundo, o arquivo aliena o indivíduo dessa memória, produzindo uma desigualdade informacional irretratável que submete os corpos a uma espécie de panóptico sobre o passado - porque a acessibilidade ao que é guardado é limitada e fragmentada para o indivíduo. Assim, se esse arquivo, prefigurado pela biblioteca de Resnais, não esquece nunca, é também porque ele faz esquecer, produzindo

\footnotetext{
12 A série Westworld (EUA, 2016), produzida e exibida pela HBO, também tem como pano de fundo de sua trama central o jogo de forças entre memória e esquecimento.

13 "Não compreendem como o divergente consigo mesmo concorda; harmonia oculta das forças opostas, como de arco e lira" (Heráclito).
} 


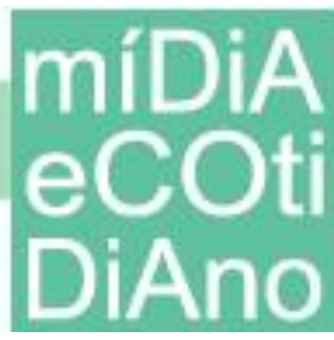

invisibilizações, controles, discernimentos que interessam para a manutenção das formas sociais vigentes.

\section{Conclusão}

Percebe-se que a atual problemática envolvendo a memória e o esquecimento no cotidiano tem alguns de seus fundamentos lançados pela assimilação da produção de conteúdo e da arquivologia ao sistema industrial, como nos mostra Alain Resnais em Toda a memória do mundo. Além disso, fica claro que essa problemática age em diversas frentes. A interface entre uma memória coletiva (ou pública) e uma individual (ou privada), isto é, um acervo "comum" composto por partes menores, fragmentadas - e que pode (até certo ponto) por estas ser acessada -, é uma dessas frentes. Assim, entendemos que a hipótese de que as mídias digitais atuam no recolhimento de experiências diversas formando uma hipermemória, passa também pelo debate sobre temas como o do direito ao esquecimento, o das possibilidades de múltiplas "camadas de ausência" nos arquivos (FRANÇA; ANDUEZA, 2018) e, no limite, até mesmo o dos ritos de luto pela morte nas mídias sociais (MELLO, 2016).

Hoje grande parte das pessoas vive no seio de uma sociedade midiatizada. O habitat contemporâneo de muitos homens e mulheres é formado muitas vezes quase que exclusivamente por um cotidiano de dispositivos digitais, gadgets eletroeletrônicos, traquitanas tecnológicas que aquecem, esfriam, apitam, comunicam, enviam, recebem, entre outras coisas. Cada vez mais, soa-nos impossível sobreviver sem nossos smartphones, nossos celulares, videogames e televisores. A dependência de uma sociabilidade calcada em redes sociais digitais é manifesta. Como aponta Vilém Flusser em Filosofia da caixa preta (1983/2011), somos todos funcionários da máquina exatamente porque a fazemos funcionar.

Especialmente no contexto das tecnologias do computador, se observarmos que os usuários têm se tornado não apenas consumidores, a ideia de funcionário faz sentido. A contínua interação em ambientes digitais vem promovendo a transformação de determinadas relações, deslocando os "internautas" também para o papel de produtores e armazenadores de conteúdo. E se hoje vivemos em uma sociedade propícia ao 


\section{míDiA

"infocontrole" e à "datavigilância", é porque participamos da lógica desse sistema (e a estimulamos, mesmo que indiretamente).

Diante do "fenômeno da estocagem de grandes volumes de dados e de sua rápida transmissão" (SODRÉ, 2012), aparentemente tornamo-nos reféns de nossas próprias criações (memórias?). Tornamo-nos, dentro da prática de produção e enquadramento de memórias (POLLAK, 1989), também figuras de fundamental importância, assim como historiadores e pesquisadores em geral. Ainda buscamos nossa deontologia própria, ética de usuários-produtores de memória cotidianos. Talvez porque tudo em nosso tempo responda à dinâmica das redes, estejamos, mais do que nunca, em um lugar privilegiado para observar e interagir com as relações de forças que promovem a história.

Todavia - e paradoxalmente - também estamos a reboque de interesses e exercícios de poder que, na maioria das vezes, estão além das disputas que formam nossos grupos de referência e de pertencimento (NAMER, 1987). E se a memória, enquanto a experiência humana de um presente que se apropria para colorir e deformar o passado (POLLAK, 1989), tem por característica a instabilidade adquirida de interpretações, reconstruções e supressões, um mundo que tudo registre talvez sabote esse aspecto. Porque, se as pessoas esquecem, a Rede, cada vez mais, parece que não.

\section{Referências}

AGAMBEN, G. O que é o contemporâneo? e outros ensaios. Chapecó, SC: Argos, 2009.

BENJAMIN, W. Magia e técnica, arte e política: ensaios sobre literatura e história da cultura. São Paulo: Brasiliense, 2012. (Obras escolhidas v.1).

BLUM, A. Tubos: o mundo físico da Internet. Rio de Janeiro: Rocco, 2013.

CARR, N. A geração superficial: o que a internet está fazendo com nossos cérebros. Rio de Janeiro: Agir, 2011.

CASTELLS, M. A sociedade em rede: a era da informação - economia, sociedade e cultura. Volume 1. São Paulo: Paz e Terra, 2010.

DIMENSTEIN, G. Volume de informação gerada por ano no mundo dobrou em três anos. Folha de S. Paulo (UOL), Jornalismo Comunitário, 04 nov. 2003. Disponível em: <http://www1.folha.uol.com.br/folha/dimenstein/noticias/gd041103h.htm>. Acesso em $24 \mathrm{de}$ outubro de 2016. 
FLUSSER, V. Filosofia da caixa preta: ensaios para uma futura filosofia da fotografia. São Paulo: Annablume, 2011.

FRANÇA, A.; ANDUEZA, N. Camadas de ausência e a produção de sentido através do cinema de arquivo. Revista do arquivo, n.6, São Paulo, abr.- 2018.

FREENET. Documentário. Direção: Pedro Ekman. Produção: Molotov Filmes. Roteiro: Pedro Ekman; Marina Pita: Idec; Intervozes; Instituto Nupef; ITS-Rio. Creative Commons (95 min). Brasil, São Paulo, 2016.

G1. Samsung registra lente de contato "smart" com câmera ativada a piscadas. Site G1, São Paulo, 06 de abr. 2016. Disponível em: <http://g1.globo.com/tecnologia/noticia/2016/04/samsung-registra-lente-de-contato-smart-comcamera-ativada-piscadas.html>. Acesso em: 10 de novembro de 2016.

HALBWACHS, M. A memória coletiva. São Paulo: Centauro, 2015.

HUYSSEN, A. Culturas do passado-presente: modernismos, artes visuais, políticas da memória. Rio de Janeiro: Contraponto : Museu de Arte do Rio, 2014.

LE GOFF, J. Documento/Monumento. In: História e memória. Campinas: SP Editora da Unicamp, 1990. p.535-549.

LÉVY, P. As tecnologias da inteligência. Rio de Janeiro: Ed. 34, 2011.

LOGAN, R. K. O que é informação?. Rio de Janeiro: Contraponto: PUC-Rio, 2012.

MARR, B. 20 fatos que sobre a internet que você (provavelmente) não sabe. Forbes Brasil, Brasil, 01 out. 2015. Disponível em: <http://www.forbes.com.br/fotos/2015/10/20-fatos-sobrea-internet-que-voce-provavelmente-nao-sabe/\#foto1>. Acesso em: 25 de outubro de 2016.

MELLO, C. A. Ritos digitais, táticas e finitude: confrontando a morte no Facebook. In: Novos olhares: revista de estudos sobre práticas de recepção a produtos midiáticos (USP), v.5, n.1, p.90-101, São Paulo, 2016.

NAMER, G. Mémoire et societé. Paris, Meridiens Klincksieck, 1987.

NORA, P. Entre memória e história: a problemática dos lugares. Projeto História. Revista do Programa de Estudos Pós-Graduados em História e do Departamento de História da PUC-SP, n. 10, p.7-28, São Paulo, dez.-1993.

NIETZSCHE, F. Genealogia da moral: uma polêmica. São Paulo: Companhia das Letras, 2008.

POLLAK, M. Memória, esquecimento, silêncio. Estudos Históricos, v. 2, n. 3, p. 3-15, Rio de Janeiro, 1989.

PLATÃO. A República. São Paulo: Edipro, 2012.

RICOEUR, P. A memória, a história e o esquecimento. Campinas: Unicamp, 2014.

ROUSSO, H. Face au passé: essais sur la mémoire contemporaine. Paris: Belin, 2016. 
SODRÉ, M. Antropológica do espelho: uma teoria da comunicação linear e em rede. Petrópolis: Vozes, 2012.

THOMPSON, J. B. A mídia e a modernidade. Petrópolis: Vozes, 2013.

TORRANO, J. A. A. Teogonia: a origem dos deuses. São Paulo: Iluminuras, 2007. 